\title{
Financial Flexibility of Universities in Adaptation to Covid-19 Challenges
}

\author{
Liudmyla Yurchyshena ${ }^{l^{*}}$, and Olexandra Laktionova ${ }^{l}$ \\ ${ }^{1}$ Vasyl' Stus Donetsk National University, Vinnytsia, Ukraine
}

\begin{abstract}
During the adaptation of universities to Covid-19, the problem of their financial flexibility has become crucial. The ability to react quickly during a pandemic crisis with changes of training format and educational activities, the flexibility to respond to external challenges under the scarce resources, maintenance of a competitive position on the market of educational services are the symptoms and implications of financial flexibility. The purpose of the article is to determine the signs of the university's financial flexibility, which could be the basis for designing and practical application of methodological tools for evaluating the financial flexibility of universities. The concept of financial flexibility of universities is proposed as the ability of university management to generate income, restrain and optimally allocate costs, generate cash flows with constrained budget funding during the crisis, create and implement business models, implement unique valuable educational proposals. Manifestations of financial flexibility concerning state and private financing have been defined. The signs of financial flexibility, such as sensitivity, efficiency, manoeuvrability, alternativeness, economy, have been outlined. Methodical tools and indicators for the evaluation of financial flexibility have been proposed. The degree of the impact of main factors on the financial flexibility of universities is determined. Keywords: financial flexibility, Universities, sensitivity, efficiency, manoeuvrability, alternativeness, economy.
\end{abstract}

\section{Introduction}

The Covid-19 pandemic has become a challenge for higher education institutions not only in terms of rapid response to changes in the format of education but also a flexible response to external challenges, given the limited opportunities for quality educational activities, the ability to create and implement value proposals, work online, service campuses. The financial consequences became noticeable not immediately but gradually, along with the loss of universities' additional income, reduction of budget allocations, reduction of the solvency of students and entrants, reduction of the number of budget places. The consequences of the pandemic for free economic zones have become a stress test for flexible response to the situation, including financial. For the first time, free economic zones have been left alone with financial problems related to revenue generation and cost containment and optimisation,

* Corresponding author: author@email.org 
changes in the university funding model, and the ability to be financially flexible in adapting to the new operation model.

Exploring the concept of «financial flexibility», Laktionova defines it as an appropriate response of the company to the manifestation of financial constraints, which has a dynamic nature, associated with the availability of capital from external sources, an adaptation of financial potential of economic entities to organisational change, management tools, financial relations [1].

According to Ang and Smedema [2] and Gamba and Triantis [3], financial flexibility is manifested in the ability of the institution to manage revenues during their reductions or fluctuations, get a positive effect from shocks, in particular, reduce external financing costs, invest, accelerate capital turnover. Ang and Smedema note the regularity that firms that can self-finance during the recession in conditions of limited access to external capital in the future will receive priorities for profitable investment [2].

Yaw M. Mensah, Robert Werner [4] determine that the efficiency of higher education institutions slows down in the absence of financial flexibility, and the degree of financial flexibility is assessed as the ratio of net assets to total assets. Researchers argue that the greater the financial constraints, the more efficiently the costs are distributed.

Scholars of China, Md Rashidul Islam, Man Wang, Leo Vashkor Dewri [5] synthesising approaches to the concept of "financial flexibility" identify it as an essential element in deciding on the capital structure, recognise the effect of financial constraints, the relationship of financial flexibility and performance in times of crisis, the relationship of financial flexibility, corporate governance and corporate social responsibility and in general, arguing for the positive effect of financial flexibility in a crisis.

The value of financial flexibility in the Covid-19 period is studied by Swiss scientists Rüdiger Fahlenbrach, Kevin Rageth, René M Stulz, arguing that firms with higher financial flexibility are better able to cover cash flow deficits due to the crisis, differentiate revenues, bear lower financial losses. As a result, financial flexibility forms certain competitive advantages of the company and their ability to be more stress-resistant to shock phenomena $[6]$.

Thus, the financial flexibility of universities is determined by the ability of university management to generate income, restrain and optimally allocate costs, generate financial flows with limited budget funding during the crisis, create and implement business models, implement unique value proposals as a result of adapting universities to new realities.

Currently, the problem of financial flexibility of universities in terms of adaptation to the challenges of Covid-19 has been studied in terms of the main trends due to these processes, but further research requires methodological tools for assessing financial flexibility and their practical application on a sample of universities.

The purpose of the article is to determine the signs of financial flexibility of the university, development, and practical application of methodological tools to assess the financial flexibility of universities.

\section{Results}

The expansion of the financial autonomy of higher education institutions poses certain challenges for university management during the period of adaptation to Covid-19. The activity of universities is realised at the expense of budgetary and private financing, resulting in a generation of financial flows.

Financial flexibility in terms of adaptation to Covid-19 has different manifestations (Fig. 1), on the one hand, universities receive limited budget funding, which is a stable source of income. However, in most cases tied to the contingent and results of free economic activities, manifestations of financial Flexibility is restraint and optimal cost allocation, as the impact 
of universities on the growth of budget funding is limited. On the other hand, the growth of private funding is an indicator of the competitiveness of free economic resources, which can generate its income through the formation of value proposals, image programs, interaction with the business environment, rapid response and the university's ability to adapt to crisis conditions.

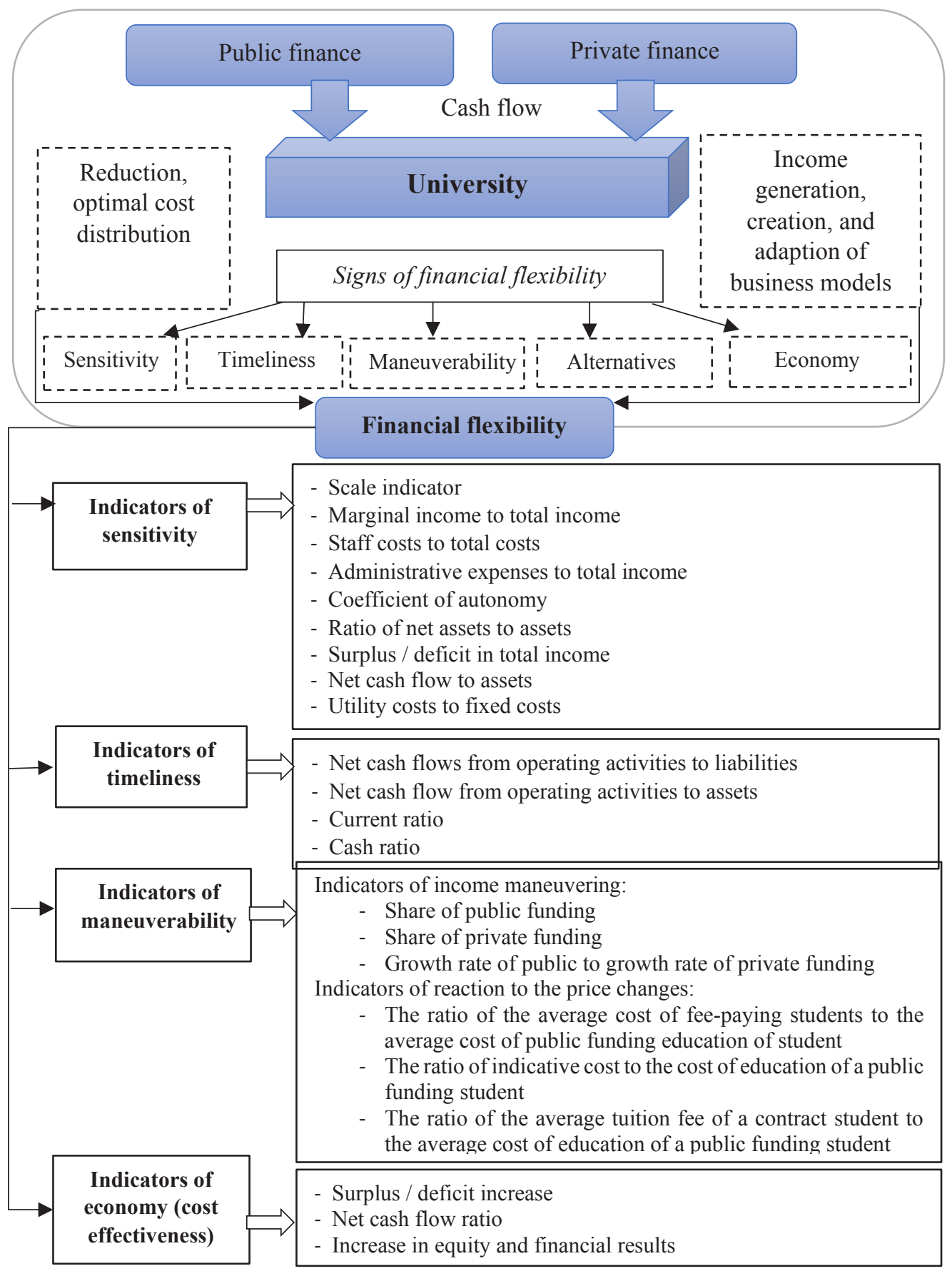

Fig. 1. Tools for evaluation of financial flexibility of university in terms of Covid-19 
From the above, we can distinguish the following signs of financial flexibility:

- sensitivity shows how universities open to a crisis influences, have reserves in financial and performance conditions and so could be flexible in the period of adaptation to the negative outcomes of Covid-19, such as changes in the contingent, reduction of special fund revenues, availability of accumulated reserves, change in cost structure, redistribution, readiness to increase certain cost items;

- efficiency shows how quickly universities respond to change and are able to produce activities in the conditions of Covid-19;

- manoeuvrability characterises the availability of free economic resources for responding to changes, quickly adaptation to new funding conditions, changing the structure of funding sources by increasing private funding, implementation new progressive value proposals;

- alternatives are manifested in the ability of university management to make alternative financial decisions, to achieve specific strategic and tactical goals through various combinations of decisions and the production of alternative activities;

- efficiency is a resultant sign of financial flexibility, which shows the cost of the university's response, which is manifested in financial results, the ability to meet financial obligations on time, the presence of positive net cash flow, the ability to accumulate funds in a crisis.

For evaluation of financial flexibility, the system of indicators could be divided into categories:

1. Sensitivity indicators characterise universities' degree of sensitivity to changes and consequences of the impact of Covid-19. This group includes the following indicators:

- the contingent of students characterises the scale indicator, and the degree of sensitivity is determined by the size of the contingent, its structure (the predominance of public funding students make it more resistant to change) and dynamics. The positive trend in the indicator reduces the level of sensitivity to the crisis caused by Covid-19;

- marginal income to total income is defined as the ratio of the difference between income, labor costs, deductions for social activities, and depreciation to the university's total income. The higher this indicator, the greater the degree of sensitivity of the university to changes in income;

- $\quad$ staff costs to total costs, the more significant the share, the greater the degree of sensitivity and the lower the level of flexibility, and vice versa. Despite the fact that such costs are variable or dependent on the contingent of students, reduction of such costs in the educational sphere is challenging, since teaching and research personnel constitute the capital and the main value of universities;

- administrative expenses to total income - the smaller this one, the more resilient universities are to change. High administrative costs lead to an increase in the sensitivity of the institution to fluctuations in income;

- coefficient of autonomy is calculated as the ratio of equity to assets. The higher the value of the indicator, the less sensitive a university to crisis phenomena;

- the ratio of net assets to assets is calculated as the ratio of assets fewer liabilities, provisions and deferred income to total assets of a university. The decrease in this indicator in the dynamics increases the level of sensitivity of universities to change, affects the ability to meet financial obligations to counterparties;

- $\quad$ surplus/deficit increase - a decrease in the dynamics or negative value is an indicator of sensitivity and is negatively reflected in the financial results of the university; 
- net cash flow to assets shows the ability of universities to form a financial cushion, the greater the value of the indicator, the more flexible the institution is, while the positive growth of the indicator in the dynamics and the value is greater than zero;

- the share of utility costs to fixed costs - the greater the share of utility costs, the greater the potential for universities savings in the period of adaptation to Covid-19, subject to the transition to online learning. All other things being equal, this indicator reduces the level of flexibility of the institution in the period of declining revenues and optimising the cost structure.

2. Indicators of timeliness show the ability of universities to finance current needs, to fulfil current financial obligations to counterparties in the face of declining revenues. Such indicators should include:

- $\quad$ net cash flow from operating activities to liabilities shows the level of ability of universities to meet current and long-term obligations; a positive value is one of the indicators of financial flexibility of the institution;

- net cash flow from operating activities to assets - the recommended value is greater than zero;

- the current ratio is calculated as the ratio of financial assets (net of long-term receivables and long-term financial investments) to current liabilities;

- cash ratio is calculated as the ratio of cash and cash equivalents of managers of budget funds and state trust funds, budget funds and other clients to current liabilities.

3. Indicators of maneuverability characterise the ability of universities to adapt to change, and include:

3.1. Indicators of income manoeuvring:

- share of public funding - the excess of the share of state funding over the average for universities in the industry is a sign of manoeuvrability, because public funding is a stable source of income to maintain the current financial stability of the university;

- share of private funding - the growth of such financing is an indicator of the competitiveness of universities on the one hand; on the other, there is a risk of dependence of private financing on Covid-19. Thus, most institutions in the period of adaptation to the pandemic reduce training costs, giving priority to funding other costs, the same trends apply to the private sector;

- growth rate of the public to growth rate of private funding - if this ratio is more than one, it has a positive effect on the financial flexibility of free economic zones and characterises their ability to change;

3.2. Indicators of reaction to the price changes show the degree of elasticity of demand in relation to changes in the indicative cost of tuition, cost of fee-paying students and the average tuition fee of a contract student. Suppose the university meets the crisis with a high tuition fee. In that case, it negatively affects the ability to manoeuvre prices, the formation of a new price to attract contract students during the financial crisis caused by Covid-19, reduces the competitiveness of high education institutions. Such indicators include:

- the ratio of the average cost of fee-paying students to the average cost of public funding education of the student

- the ratio of indicative cost to the cost of education of a public funding student

- the ratio of the average tuition fee of a contract student to the average cost of education of a public funding student

4. Cost-effectiveness indicators show whether universities are able to adapt to the challenges of the Covid-19 pandemic, which is manifested in the positive values of indicators and their dynamics: 
- increase in surplus / deficit - a positive value and increase in the dynamics is a stimulating indicator of financial flexibility of the university;

- net cash flow ratio is calculated as the ratio of net cash flow to the assets, shows the degree of replenishment of funds due to net cash flow;

- the increase in equity and financial results is the result of practical activities of the university, which is ensured by balancing revenues and expenditures, including optimisation in the period of Covid-19.

The assessment of the level of financial flexibility according to the system of proposed indicators should be calculated based on an integrated indicator by standardising indicators and ranking them according to the degree of impact. The conditions were met during rationing: for the stimulating indicators, the increase of which leads to an increase in financial flexibility, the minimum value was applied; for the destimulators the increase which leads to a decrease in flexibility, the maximum value is applied.

For the evaluation of financial flexibility, the official data of 24 universities of Ukraine (classical (CU), economic (EU), polytechnic (PU), pedagogical (PedU), others (OU)) and 19 indicators were applied. Indicators for the calculation of which are missing in the official financial statements and are internal management information (administrative costs to total income, the utility costs to fixed costs and indicators of response to the price factor) in the calculation of integrated indicator were omitted. As a scale indicator, the contingent of universities on the first of October of the respective year was taken [7]. When determining the integrated indicator, its logarithm was performed, and the decimal logarithm was calculated to bring the data to a single array.

The integrated indicator was determined separately for 2019 and 2020; the average value of the integrated indicator and rationing was carried out over a set of years. The results of the $\underset{0,35}{\text { integrated indicator are presented in Figure } 2 .}$

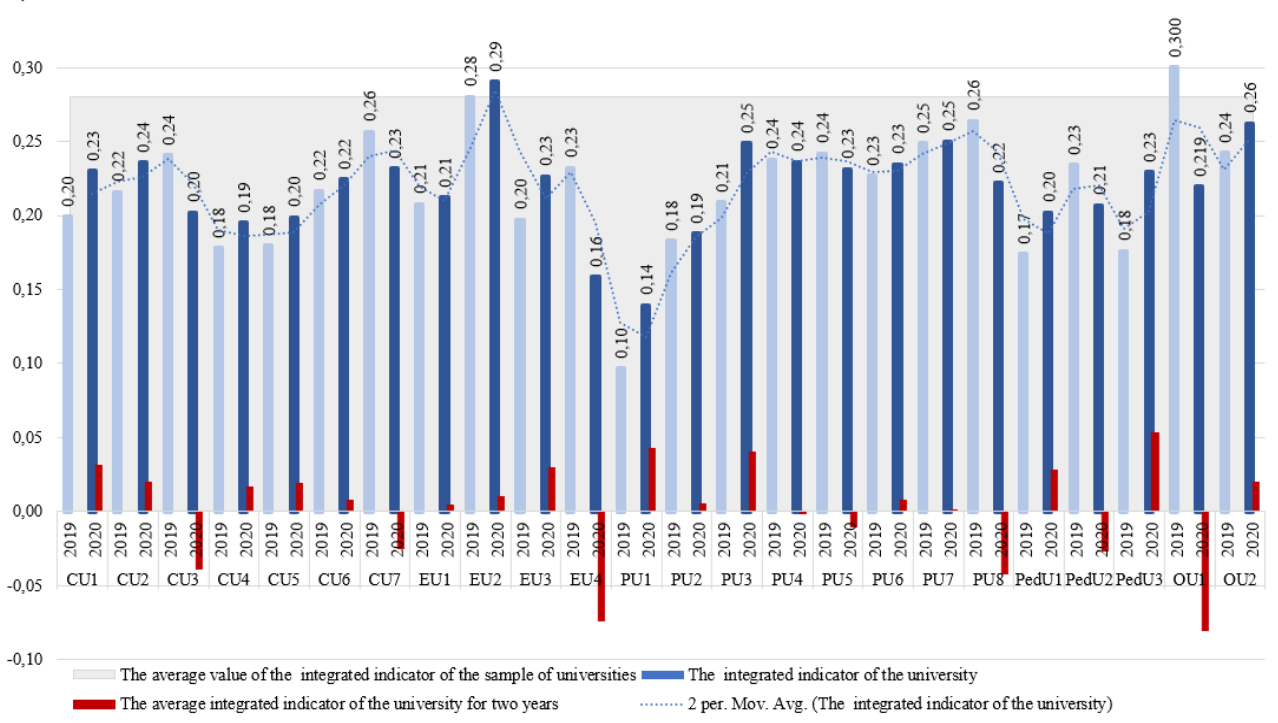

Fig. 2. An integrated indicator of the financial flexibility of universities

The obtained average value of the integrated indicator for 2019-2020 is 0.28 , so we will assume that universities with a value above the average are more financially flexible than others. The highest level of financial flexibility among classical universities in 2019 is demonstrated by CU7, which is 0.40 . However, in 2020 the integrated indicator decreased by 0.06 due to a reduction in the scale (reducing the number of students by $22 \%$ ), which negatively affected growth rates of public and private funding, increasing the budget deficit 
and the share of staff costs to total costs. The level of financial flexibility of CU2 increases during 2019-2020 from 0.27 to 0.29 due to a positive increase in the contingent by $2 \%$, the transition to a surplus zone, a positive increase in equity and financial results, an increase in the replenishment ratio by eight times. The high level of the integrated indicator for CU3 was set at 0.30 in 2019 , but the effects of Covid-19 violated the level of financial flexibility by 0.05 to 0.25 .9 The increase in the scale by $6 \%$ with a simultaneous change in the structure by $3 \%$ towards the growth of private funding by 0.02 , affected the growth rate of private funding by $0.5 \%$, reducing the growth rate of budget funding by $16.6 \%$. An insufficient level of financial flexibility in the group of classical universities is demonstrated by CU1, CU4, CU5, the level of the integrated indicator, despite the positive dynamics, is below the average value and is 0.23 in $2020 ; 0.25 ; 0.27$ respectively. This is due to the reduction of scale indicators, growth rates of public financing, growth of equity and financial results, the budget deficit, fluctuations in other indicators.

The financial flexibility of economic universities depends on the indicators of the reaction to the price factor because the gap between the cost of education of public funding students, a fee-pay student and the indicative cost significantly affect universities' income. The change in scale ambiguously affects the integrated indicator, and therefore for economic universities, the scale indicator is not a determining factor, but to a greater extent, is determined by its structure and cost of education. For example, despite an increase in scale by $11 \%$, the financial flexibility of the EU4 decreased from 0.30 to 0.22 due to a reduction in the growth rate of private funding and income of the university. The reduction of the contingent by $5 \%$ in the EU3 did not have a negative impact on the financial flexibility of the university, which increased during 2019-2020 from 0.24 to 0.28 , as the reduction of private funding growth while increasing the public funding had a positive impact on the integrated indicator, that confirms the influence of price indicators.

The high level of financial flexibility is inherent in polytechnic universities, PU1-PU7 show a positive increase in the integrated indicator, but PU1 and PU2 have an insufficient level of financial flexibility, which is in 2020 are 0.19 and 0.25 , respectively. This is due to a slight reduction in the contingent, a decrease in the growth rate of private and budget funding. The high share of public funding, scale and cost of the public funding student are positive factors of financial flexibility.

The integrated indicator of financial flexibility for pedagogical universities is below the average of $0.26-0.25$ in 2020. For the other group, it includes the National University of Food Technologies (IU1) and the National University of Life and Environmental Sciences of Ukraine (IU2), which demonstrate above the average of the sample of universities, the level of the integrated indicator in 2020 is 0.29 and 0.30 , respectively.

Assessment of financial flexibility indicators for the sample of universities indicates an insufficient level of financial management in the high education institutions, which with the expansion of autonomy do not carry out medium-term planning of financial resources, evidence of sharp fluctuations, budget deficit, negative net cash flow, etc. The most important indicator influencing the financial flexibility and sustainability of universities is the contingent, which during the pandemic period was significantly reduced in regional institutions. Given that the financing of Ukrainian high education institutions is tied to the contingent, the last one has significantly affected their financial support. These trends disrupt the financial balance of the universities and reduce the level of financial flexibility during the period of adaptation to Covid-19.

The results of the correlation analysis showed that the degree of connection between the indicators of financial flexibility and the integrated indicator is not high and not more than 0.6 (Fig. 3).

A significant correlation at the level of $0.40-0.52$ is observed with respect to autonomy ratios, the ratio of net assets to assets, liquidity ratios. A weak negative correlation between 
-0.10 and -0.27 is observed between the integrated indicator and the marginal revenue indicator, the share of staff costs to total costs and the share of private financing. For other indicators, there is a weak correlation between 0.38 and 0.38 . The results of the correlation analysis showed significant numbers of correlations of the same indicators in 2019-2020, which is a sign of the sensitivity of universities to the effects of Covid-19.

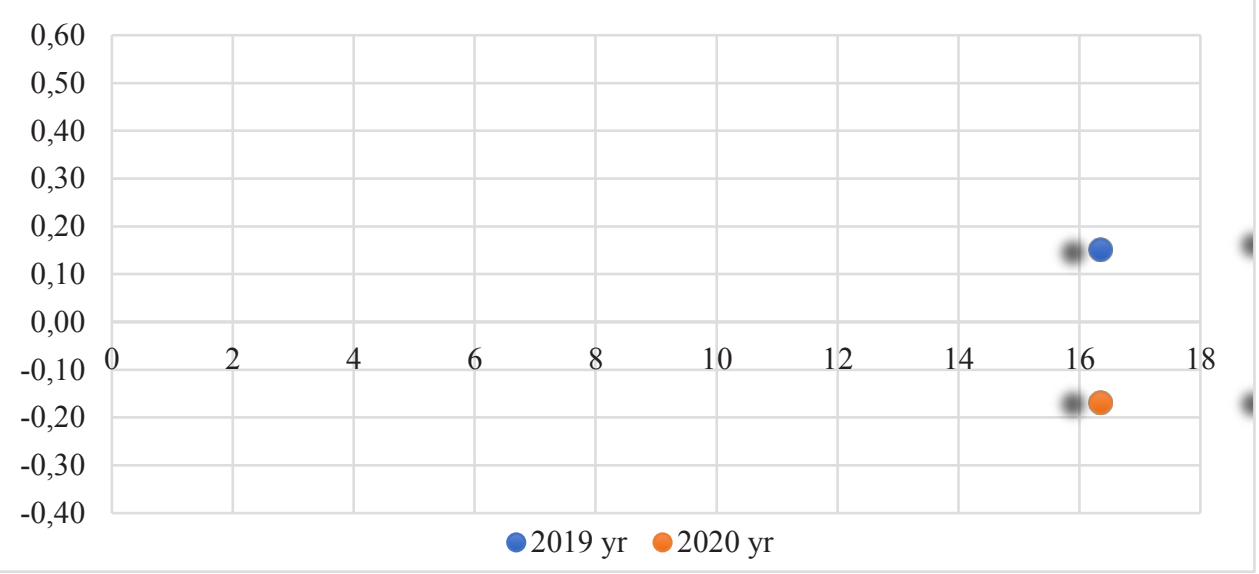

Fig. 3. Results of correlation analysis of financial flexibility indicators

Thus, the financial flexibility of the university is determined not only by quantitative indicators but also qualitative, the ability of university management to make decisions about the formation of the required value proposals in terms of adaptation to Covid-19. Decisionmaking is carried out under the influence of external and internal factors, which in turn are divided into productive (direct, indirect) and behavioural [8]. Behavioural factors significantly affect the level of financial flexibility, namely the effectiveness of university management, the ability to interact with stakeholders, academic reputation, quality of organisation during the adaptation to Covid-19, irrationality of expectations, motivation of potential applicants, regional factor, effect scale, location of the university, etc. Regional universities are more sensitive to the crisis than central ones.

\section{Conclusions}

The financial flexibility of universities in adapting to Covid-19 has different manifestations in terms of public and private funding. Ukrainian universities are financed mainly by public allocations, which depend on the number of students and performance indicators, which reduces the level of financial flexibility, which is manifested through the ability of educational institutions to restrain and optimally allocate costs. Regarding private funding, their share in universities ranges from 17 to $72 \%$, with an increase in the share of economic universities, which poses particular challenges to their resources. To maintain a stable position and ensure expanded reproduction, it is necessary to maintain leading positions in the market of educational services, provide quality educational services.

The results of the practical approbation showed that the clear indicators for the financial flexibility of universities are changes in the volume and structure of the contingent, not only in terms of public and private funding but also in terms of specialities, taking into account the price factor (tuition fees and contract prices). The results of the analysis revealed that the reduction of the contingent and the change in the structure of funding in different ways affect the change of the integrated indicator of financial flexibility for different groups of universities due to the list of specialities and their cost. 
The level of financial flexibility of universities and its manifestation is the ability to generate their own income, generate value proposals, interact with the business environment, respond quickly and adapt to crisis conditions, implement business models, act in new situations.

The proposed methodological tools for assessing the financial flexibility of the university in terms of adaptation to Covid-19 considers the signs of financial flexibility, distinguish four groups of indicators with indicators for their evaluation: sensitivity, efficiency, manoeuvrability, economy.

The methodological tools were tested in a sample of 24 universities, financial flexibility indicators were calculated, and an integrated financial flexibility indicator at the Covid-19 input was determined, taking into account the consequences of the impact. It was found that the ambiguous dynamics and importance of indicators of financial flexibility, manifestations of atypical for some universities financial indicators are due to changes in the structure of funding and the contingent of students. Such trends have affected financial flexibility and so on the financial results of universities in different ways.

Further research should be aimed at modelling the effects of Covid-19, considering the price indicator and changing the structure of the contingent on the financial stability of universities as an indicator of financial flexibility.

\section{References}

1. O. Laktionova. Flexibility of the financial system: methodology, evaluation and vectors of provision. (Vinnytsia, Ukraine, 2016).

2. J. Ang, A. Smedema, Journal of corporate Finance, 17(3), (774-787). (2011). DOI: $10.1016 /$ j.jcorpfin.2011.02.001.

3. A. Gamba, A. Triantis, Forthcoming Journal of Finance, 63 (5), (2008). DOI: 10.1111/j.1540-6261.2008.01397.x.

4. Yaw M. Mensah, R. Werner, Journal of Accounting and Public Policy 22 (4), (293323). (2003). DOI: 10.1016/S0278-4254(03)00036-X.

5. R. Islam, M. Wang, L. Dewri, International Journal of Accounting and Financial Reporting, 9, (245-256). (2019). DOI: 10.5296/ijafr.v9i1.13195.

6. R. Fahlenbrach, K. Rageth, R. M Stulz, The Review of Financial Studies, 34 (11), (5474-5521). (2020). DOI: 10.1093/rfs/hhaa134.

7. The only state electronic database on education, 2021. URL: https://registry.edbo.gov.ua/opendata/educators/

8. L Shaulska, L. Yurchyshena, Y. Popovskyi. Using MS Power BI tools in the university management system to deepen the value proposition, in Procceding of the 11th International Conference on Advanced Computer Information Technologies, 2021, ACIT (2021). DOI: 10.1109/ACIT52158.2021.9548447. 